\title{
The novel ethylene antagonist, 3-cyclopropyl-1-enyl-propanoic acid sodium salt (CPAS), increases grain yield in wheat by delaying leaf senescence
}

\author{
Moshe Huberman • Joseph Riov • Eliezer E. Goldschmidt • \\ Akiva Apelbaum • Raphael Goren
}

Received: 3 October 2013/Accepted: 16 December 2013/Published online: 24 December 2013

(C) The Author(s) 2013. This article is published with open access at Springerlink.com

\begin{abstract}
The present report describes the effect of 3-cyclopropyl-1-enyl-propanoic acid sodium salt (CPAS-WO 2010/0822930), a novel water soluble ethylene antagonist, on senescence and grain yield of several cultivars of common wheat (Triticum aestivum L.) and durum wheat (T. durum Desf.). CPAS abolished ethyleneinduced leaf and ear organ senescence, as evidenced by the inhibition of chlorophyll degradation. CPAS application to wheat plants grown under controlled $\left(120 \mathrm{mg} \mathrm{L}^{-1}\right)$ or field conditions $\left(110 \mathrm{mg} \mathrm{L}^{-1}\right)$ significantly increased grain yield in the range of 9-13\% and 3-45\%, respectively, depending on treatment and variety. The CPAS-induced increase in grain yield was usually more significant under extreme weather conditions. In some cases spraying once at the medium milk stage was sufficient to obtain the maximum increase in grain yield, while in other cases spraying twice at the medium and late milk stages yielded the highest increase. The above data support the common view, that there is a positive causal relationship between the delay of leaf and ear organ senescence and grain yield. The results of the present study demonstrate that CPAS can effectively be used to increase wheat grain yield, and possibly the yield of other field crops, under field conditions.
\end{abstract}

This paper is dedicated to Prof. Edward C. Sisler from North Carolina State University USA, for introducing me thirty years ago to the subject of ethylene antagonist research. Prof. R.Goren.

M. Huberman · J. Riov · E. E. Goldschmidt · A. Apelbaum · R. Goren $(\square)$

Robert H. Smith Institute of Plant Sciences and Genetics in Agriculture, Robert H. Smith Faculty of Agriculture, Food and Environment, The Hebrew University of Jerusalem,

7610001 Rehovot, Israel

e-mail: rgoren@agri.huji.ac.il
Keywords Chlorophyll · Ethylene antagonist - Grain weight . Senescence . Wheat

\begin{abstract}
Abbreviations
CPAS 3-cyclopropyl-1-enyl-propanoic acid sodium salt 1-MCP 1-methylcyclopropene
\end{abstract}

\section{Introduction}

In wheat, as in other cereals, the period of grain filling is limited by the onset of senescence of the flag leaves and the vegetative parts of the ears after anthesis. The rapid senescence of these organs is characterized by chlorophyll degradation and reduced photosynthetic capacity (Labrana and Araus 1991; Beltrano et al. 1994, 1998, 1999). It has long been demonstrated that the duration of the grain filling period in wheat is positively correlated with yield (Solansky 1978; Wiegan and Cuellar 1981), and shortening of this period by accelerating senescence reduces grain weight (Beltrano et al. 1994, 1998, 1999; Gelanga et al. 2000). These data are supported by the observations that 'stay green' mutants of durum wheat, which maintained photosynthetic competence for longer time than the parental line, attained a higher grain weight (Spano et al. 2003). Therefore, there is a potential for increasing grain yield by delaying chlorophyll degradation, and thereby extending the grain filling period.

Ethylene is recognized as one of the main factors that trigger the onset of leaf senescence (Abeles et al. 1992). Although the pattern of ethylene production differs between various wheat cultivars, there is a clear evidence that the vegetative organs of all wheat cultivars produce ethylene under normal conditions during development, including the grain filling period (Wheeler et al. 1996; 
Labrana et al. 1991; Beltrano et al. 1994, 1998, 1999; Dias et al. 2010). Several types of evidence indicate that ethylene accelerates the senescence of the vegetative organs of wheat during grain filling, and hence reduces grain yield. Firstly, exogenous ethylene accelerated senescence, as was evident by the rapid chlorophyll degradation in the flag leaves and the vegetative parts of the ears (Beltrano et al. 1994), and reduced grain yield (Cox and Otis 1989; Beltrano et al. 1994, 1999; Klassen and Bugbee 2002). Secondly, inhibitors of ethylene biosynthesis or action delayed senescence of the vegetative organs (Labrana and Araus 1991; Labrana et al. 1991; Beltrano et al. 1994) and increased grain weight (Beltrano et al. 1994, 1999).

In the above mentioned reports, ethylene production by various wheat organs was measured in plants grown under controlled conditions. In field grown plants, ethylene production might be enhanced by exposure to environmental stresses, such as drought and heat or a combination of both. Data concerning the effects of water stress on ethylene production in wheat are inconsistent. While some reported that water stress increased ethylene production by the flag leaves and ears (Beltrano et al. 1997, 1999) or grains (Yang et al. 2006), others reported that water stress had no effect (Narayana et al. 1991) or even decreased (Balota et al. 2004) ethylene production by whole plants. Beltrano et al. (1999) reported that water stress significantly decreased grain yield, and this decrease was completely reversed by an inhibitor of ethylene biosynthesis. The effect of heat stress on ethylene production and grain yield was also studied in various wheat cultivars. Exposure of heat susceptible cultivars to high temperatures significantly increased ethylene production by the flag leaves and grains (Hays et al. 2007; Dias et al. 2010) and decreased grain yield, which was reversed by 1-methylcyclopropene (1-MCP), an antagonist of ethylene action (Hays et al. 2007).

A recently introduced new water soluble ethylene antagonist, 3-cyclopropyl-1-enyl-propanoic acid sodium salt, effectively delayed flower senescence and fruit ripening induced by endogenous and exogenous ethylene (Goren et al. 2011). This ethylene antagonist seems to be superior to 1-MCP, the currently most common ethylene antagonist, for application to plants grown in open spaces, such as greenhouses and fields. Although 1-MCP can be applied as a wettable powder, it is released as a gas after application, and therefore its efficacy is unpredictable. Generally, excessive concentrations are being used to obtain the desirable results, which might pose a threat to nearby crops (Burns 2008). These problems are avoided by the application of 3-cyclopropyl-1-enyl-propanoic acid sodium salt (CPAS), since it is a water soluble salt.

The present report demonstrates that CPAS significantly increased the grain yield of several wheat cultivars grown under controlled and field conditions. This effect might have resulted from extending the grain filling period by delaying the senescence of the flag leaves and the vegetative parts of the ears, as was evident by the inhibition of ethylene-induced chlorophyll degradation by CPAS.

\section{Materials and methods}

\section{Plant material}

Common wheat (Triticum aestivum L., cv. Bet Hashita and Gedera, early and mid-early cultivars, respectively) and durum wheat (T. durum Desf. cv. Gvati and Galil, both mid-late cultivars) were used in the present study. These spring cultivars were developed in Israel for cultivation under Mediterranean climate.

\section{Experiments under controlled conditions}

Gedera seedlings were grown in a phytotron in $600-\mathrm{mL}$ pots filled with a local sandy soil under a 16-h day length and $22 / 18{ }^{\circ} \mathrm{C}$ day/night temperature. Each pot contained two seedlings. The seedlings were irrigated daily with tap water and once a week with a half-Hoagland nutrient solution.

For testing the ability of CPAS to abolish the ethyleneinduced chlorophyll degradation, the upper part of the plants, which included the ears, the flag leaves, and the uppermost leaves beneath the flag leaves was sprayed with various concentrations of CPAS in $20 \mathrm{mM}$ of K-phosphate buffer, $\mathrm{pH} 7.6$, at the medium milk stage followed by spraying with $750 \mu \mathrm{L} \mathrm{L}^{-1}$ ethephon $24 \mathrm{~h}$ later. All spraying solutions contained $0.1 \%$ Kinetic surfactant (Helena Chemical Company, TN, USA). The control was sprayed at medium milk stage with the same solution without the inhibitor. Samples of leaves and the vegetative parts of the ears were taken for the determination of chlorophyll content 7 days after the termination of the ethephon treatment. The chlorophyll analysis was performed in 8 replicates of one plant each.

For examining the effect of CPAS on the grain yield, seedlings were sprayed with $120 \mathrm{mg} \mathrm{L}^{-1}$ CPAS as described above at the following stages: medium milk, late milk, twice at the medium and late milk, and early dough. At maturity, 50 ears of each treatment were hand threshed, and the average grain weight was determined.

\section{Field experiments}

Field experiments were carried out during two seasons, 2008-2009 and 2009-2010, in the experimental farm of the Volcani Center, Agricultural Research Organization, BetDagan, Israel. The experimental farm is characterized by a medium-heavy soil. Before sowing, the experimental site was sprayed with $200 \mathrm{~g} \mathrm{ac}^{-1}$ of Aurora Turbo (mecoprop-p) 
Table 1 Effect of $120 \mathrm{mg} \mathrm{L}^{-1}$ CPAS applied at different grain developmental stages on the grain yield of $\mathrm{cv}$

\begin{tabular}{|c|c|c|c|c|}
\hline \multirow[t]{2}{*}{ Treatment stages } & \multicolumn{4}{|l|}{ Grain yield } \\
\hline & $\mathrm{g} \mathrm{ear}^{-1}$ & $\begin{array}{l}\% \text { of } \\
\text { Control }\end{array}$ & $\begin{array}{l}1,000 \text {-grain } \\
\text { weight }(\mathrm{g})\end{array}$ & $\begin{array}{l}\% \text { of } \\
\text { Control }\end{array}$ \\
\hline Control & $2.15 \pm 0.05 \mathrm{c}$ & 100.0 & $43.2 \pm 0.5 \mathrm{c}$ & 100.0 \\
\hline Medium-milk & $2.33 \pm 0.04 \mathrm{~b}$ & 108.7 & $47.1 \pm 0.7 \mathrm{~b}$ & 109.0 \\
\hline Late-milk & $2.46 \pm 0.04 \mathrm{a}$ & 114.5 & $48.8 \pm 0.6 \mathrm{a}$ & 113.1 \\
\hline $\begin{array}{l}\text { Medium- and } \\
\text { late-milk }\end{array}$ & $2.47 \pm 0.06 \mathrm{a}$ & 115.0 & $48.9 \pm 0.5 \mathrm{a}$ & 113.2 \\
\hline
\end{tabular}

Galil grown under field conditions (2008-2009 season). CPAS was applied at the medium, late, and both medium and late milk stages. The control was sprayed at the medium milk stage with the treatment solution without CPAS. At maturity two groups of 100 ears were randomly selected from each treatment plot and hand threshed for the determination of the grain weight per ear. The rest of the ears were mechanically threshed for determination of the 1,000-grain weight. Vertical bars indicate plus or minus SE of the means $(n=6)$

herbicide (Luxembourg Industries, Israel). After emergence, the wheat seedlings were sprayed with $1 \mathrm{~L} \mathrm{ac}^{-1}$ thionex (endosulfan) insecticide (Makhteshim Agan Group, Israel).

\section{8-2009 Season}

Cv. Galil was sown in mid-December, 2008. Before applying CPAS, six blocks were randomly selected and each block was further randomly divided to four treatment plots, $4 \mathrm{~m}^{2}$ each. One and half-m-wide strips of untreated plants separated the treatment plots from each other. CPAS was applied on the upper part of the plants, with a hand sprayer at a concentration (about $0.4 \mathrm{~L} \mathrm{~m}^{-2}$ ) of $120 \mathrm{mg} \mathrm{L}^{-1}$ in $20 \mathrm{mM}$ of K-phosphate buffer, $\mathrm{pH} 7.6$, containing $0.1 \%$ of Kinetic surfactant. CPAS was applied at the following stages: medium milk, late milk, and twice at the medium and late milk. The control was sprayed with the same solution without the inhibitor at the medium milk stage.

At full maturity, the ears of each of the six treated blocks were separately harvested. Two groups of 100 ears were harvested from each treatment plot and hand threshed. The grain number and weight were separately determined for each ear, and the data served to calculate the grain yield expressed as $\mathrm{g} \mathrm{ear}^{-1}$ and the average grain weight of each ear. The number of ears with the same average grain weight of each treatment was expressed as percent of total ear number. The rest of the ears were mechanically threshed for determination of the 1,000-grain weight of 5 replicates for each plot.

\section{9-2010 Season}

Cv. Galil, Bet-Hashita, and Gvati were sown at the end of November, 2009. The experimental design was similar to that of the previous season, except that the size of the treatment plots was $6.25 \mathrm{~m}^{2}$. CPAS at a concentration of $110 \mathrm{mg} \mathrm{L}^{-1}$ was applied as described above. At full maturity, the timing of which differed between the various cultivars, the harvesting and calculation of the data were performed as described above, except that two groups of 200 ears were used for calculating the grain yield per ear and the average grain weight of each ear.

The grain yield in the field experiments was measured by the 1,000-grain weight, weight per ear, and the average grain weight of each ear. Since the data obtained by the last two parameters resembled those of the 1,000-grain weight, we presented them only in the first field experiment (Table 1 and Fig. 4). In all the other field experiments only the 1,000-grain weight data are presented.

\section{Chlorophyll analysis}

For chlorophyll determination, 4-5 leaf discs, 6-mm in diameter, and 6 glumes or chaffs were sampled. The plant samples were extracted in $5 \mathrm{~mL}$ of dimethylsulfoxide according to Hiscox and Israelstam (1979) and Ben-Yaakov et al. (2006), and the chlorophyll content of the extract was determined by spectrophotometric analysis at $652 \mathrm{~nm}$. The chlorophyll content is expressed as $\mathrm{mg} 100 \mathrm{mg}^{-1}$ fresh weight.

\section{Statistics}

Vertical bars are plus or minus SE of the means. Bars with different letters are significantly different at $p<0.05$. The significance level was analyzed using JMP program.

\section{Results}

Experiments under controlled conditions

As mentioned in the introduction, it is well established that ethylene accelerates the senescence of the vegetative organs and tissues of wheat during the grain filling period, resulting in reduced grain yield. Therefore, we first studied the efficacy of CAPS to abolish the ethylene-induced chlorophyll degradation. Spraying cv. Gdera plants with $750 \mathrm{~mL} \mathrm{~L}^{-1}$ ethephon at the medium milk stage significantly reduced chlorophyll content, except for the flag leaves, in which the reduction was not significant (Fig. 1). Of the various CAPS concentrations examined, $45 \mathrm{mg} \mathrm{L}^{-1}$ completely reversed the ethylene-induced chlorophyll degradation in the flag leaves, uppermost leaves, and chaffs, while in the glumes only a partial, but significant, reversal was obtained. CAPS concentration of $135 \mathrm{mg} \mathrm{L}^{-1}$ also completely reversed the ethylene-induced chlorophyll degradation in the flag and uppermost leaves, which is also demonstrated by the color 


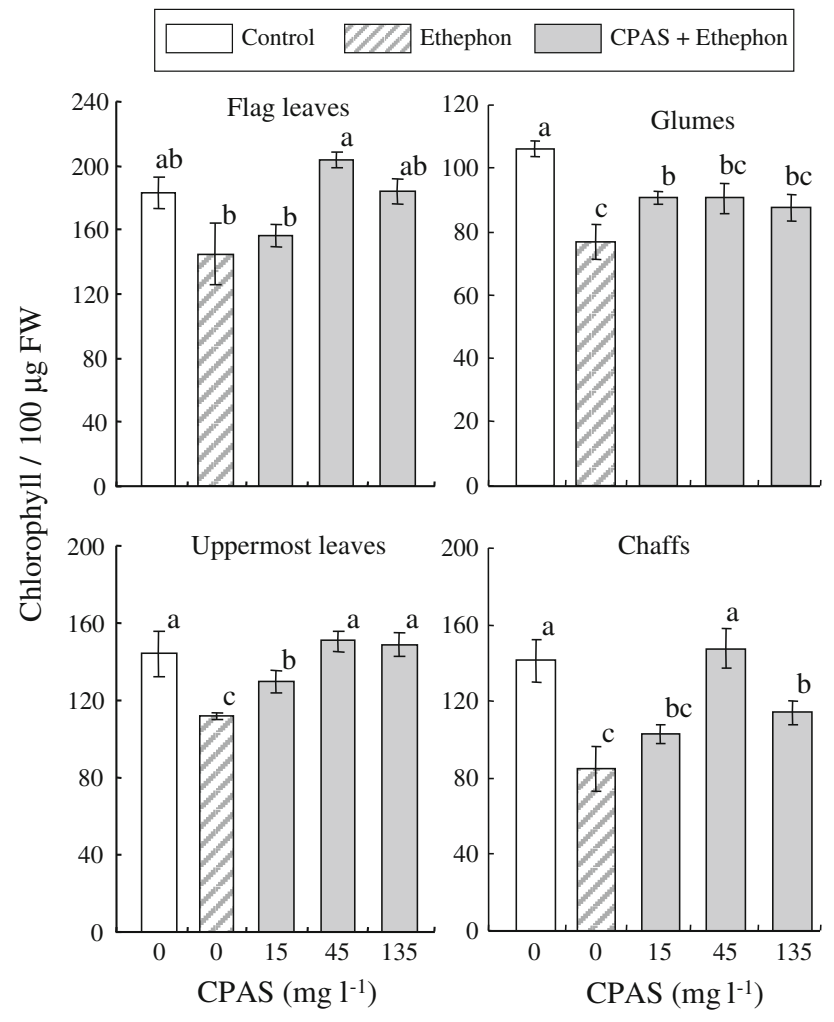

Fig. 1 Effect of CPAS on ethephon-induced chlorophyll degradation in leaves and ears cv. Gdera plants grown under controlled conditions. Plants were sprayed at the medium milk stage with various concentrations of CPAS followed by spraying with $750 \mu \mathrm{L} \mathrm{L}^{-1}$ ethephon $24 \mathrm{~h}$ later. The chlorophyll content was determined 7 days after the termination of treatments. Vertical bars indicate plus or minus SE of the means $(n=8)$

change of the leaves (Fig. 2). The lowest concentration examined, $15 \mathrm{mg} \mathrm{L}^{-1}$, partly reversed the ethephon-induced chlorophyll degradation, but its effect was significant only in the uppermost leaves and glumes.

To determine the effect of CAPS on the average grain weight, cv. Gdera plants were sprayed with $120 \mathrm{mg} \mathrm{L}^{-1}$ of the inhibitor either once or twice at various milk stages. All CAPS treatments significantly increased the grain yield by about $18-22 \%$ compared to the control, with no significant differences between treatments (Fig. 3).

\section{Field experiments}

Based on the data obtained under controlled conditions, we conducted field experiments with several cultivars during two growing seasons to assess the effect of CPAS on the grain yield under field conditions.

\section{8-2009 season}

In the 2008-2009 season, the effect of CPAS on the grain yield was examined using cv. Galil. All CPAS treatments



Fig. 2 Effect of $135 \mathrm{mg} \mathrm{L}^{-1}$ CPAS applied at the medium milk stage on the color of ethephon-treated flag (upper) and uppermost (lower) leaves of cv. Gdera grown under controlled conditions. The ethephon treatment was applied $24 \mathrm{~h}$ later to CPAS-untreated control $(\mathbf{a}, \mathbf{b})$ and CPAS-treated $(\mathbf{c}, \mathbf{d})$ plants. The photographs were taken 7 days after the termination of treatments

significantly increased the grain weight per ear by 8.7-15\% compared to the control (Table 1). Data for the 1,000-grain weight were quite similar to the former data. The maximum increase in yield was obtained in plants treated at the late milk and at both the medium and late stages, which was significantly higher than that obtained in plants treated at the medium milk stage. The ear distribution curve, which is based on the average grain weight per ear, shifted to a higher average grain weight when CPAS was sprayed at the late milk stage (Fig. 4). A similar effect was also obtained with the other two CPAS treatments (data not shown).

\section{9-2010 Season}

In the 2009-2010 season, we examined the effect of CPAS on the grain yield in three cultivars: Galil, Bet Hashita, and Gvati, which were treated with CPAS at the same grain developmental stages as in the previous season. The 2009-2010 season was characterized by a relatively low annual rainfall, $338 \mathrm{~mm}$ compared to $515 \mathrm{~mm}$ in the 2008-2009 season, and elevated temperatures during the grain filling period. As a result, a relatively large number of 

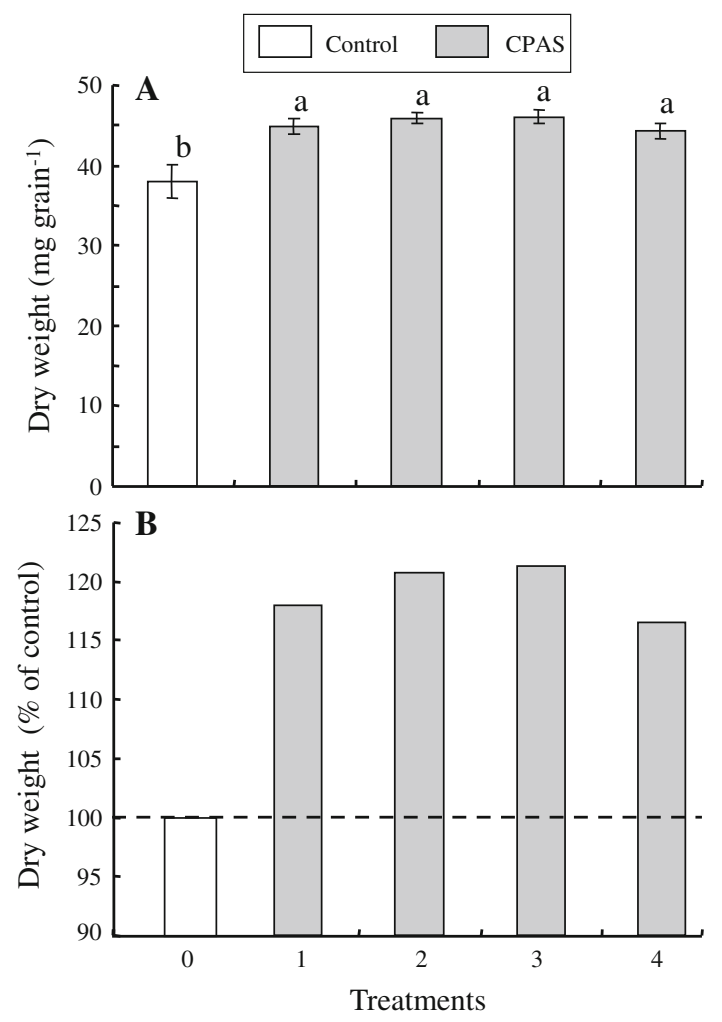

Fig. 3 Effect of $120 \mathrm{mg} \mathrm{L}^{-1}$ CPAS applied at different grain developmental stages on the average grain weight of cv. Gdera plants grown under controlled conditions. CPAS was applied at the following stages: 1-medium milk; 2-late milk; 3-at both medium and late milk; 4-7 days later. At maturity, ears were hand threshed, and the average grain weight was determined. a average grain weight. b average grain weight as percentage of control. Vertical bars indicate plus or minus SE of the means $(n=50)$

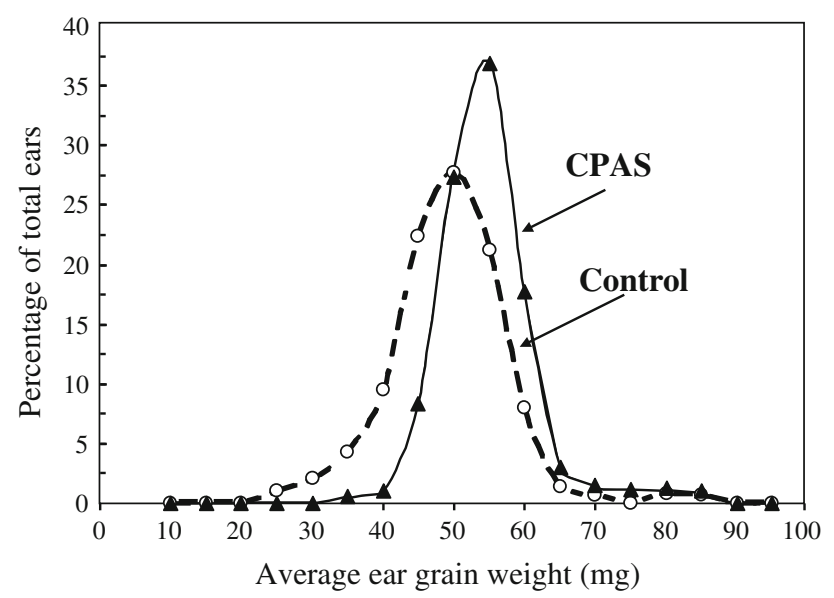

Fig. 4 Effect of $120 \mathrm{mg} \mathrm{L}^{-1}$ CPAS applied at both the medium and late milk stages on the average grain weight of each ear of cv. Galil grown under field conditions (2008-2009 season). Plants were treated with CPAS as described in the legend of Table 1. One hundred ears were randomly sampled from each treatment plot. The grains of each ear were separated from their glumes and chaffes, counted, and their weight was recorded. The data are presented as the distribution of ears with the same average grain weight as percentage of total ear number ears did not reach their regular size, and the grain yield data were separately determined for regular $(7.5-9.6 \mathrm{~cm}$ long) and small (5.0-6.4 cm long) ears. Generally, CPAS significantly increased the grain yield in almost all the treatments examined, but the response of the various cultivars to the timing of the treatment differed between them.

All treatments with CPAS significantly increased the grain yield of both the regular and small ears of cv. Galil (Table 2). The highest and significant increase in yield expressed as grain weight per ear or 1,000-grain weight of regular ears was obtained following spraying twice at both the medium and late milk stages, being $33.1 \%$, compared to the control. The data for the small ears indicate that spraying at the medium milk stage was enough to obtain the maximum effect.

Although cv. Bate Hashita matures 2 weeks earlier than cv. Galil, its 1,000-grain weight was higher (Table 2). All CPAS treatments significantly increased the 1,000-grain weight of both the regular and small ears, but the increase was much more prominent in the small ears, reaching more than $30 \%$ compared to about $10 \%$ in the regular ears. One spray of CPAS at the medium milk stage was enough to obtain the maximum increase in yield in both types of ears.

The mid-late maturing durum cv. Gvati is characterized by a relatively high yield 1,000-grain weight (Table 2). Almost all CAPS treatments significantly increased the 1,000-grain weight of both the regular and small ears. The maximum yield increase in the regular ears was obtained by spraying twice at the medium and late milk stages, being about $45 \%$ compared to the control. The effect of all CPAS treatments on the grain yield of the small ears was much less prominent than that obtained in the regular ears, but except for the treatment at the late milk stage, the increase in yield was significant. One spray of CPAS at the medium milk stage brought about the maximum yield increase in the small ears, but it was not significant from that obtained by spraying twice at the medium and late stages.

\section{Discussion}

The natural hormone ethylene has adverse preharvest and postharvest effects on a wide range of agricultural crops. Therefore, inhibitors of ethylene action are both potentially beneficial for agricultural use, since they protect the tissues from endogenous and exogenous ethylene (Sisler and Serek 1997). There is a large number of observations demonstrating that ethylene accelerates the senescence of the vegetative organs of wheat during the grain filling period, and hence reduces grain yield (Cox and Otis 1989; Beltrano et al. 1994, 1999; Klassen and Bugbee 2002). Inhibitors of ethylene biosynthesis or action delayed the 
Table 2 Effect of $110 \mathrm{mg} \mathrm{L}^{-1}$ CPAS applied at different grain developmental stages on the 1,000-grain weight of cv

\begin{tabular}{|c|c|c|c|c|c|c|}
\hline \multirow[t]{2}{*}{ Treatment stages } & \multicolumn{2}{|l|}{ GALIL } & \multicolumn{2}{|l|}{ BAIT HSHITA } & \multicolumn{2}{|l|}{ GVATI } \\
\hline & 1,000 -grain weight $(\mathrm{g})$ & $\%$ of control & 1,000 -grain weight $(\mathrm{g})$ & $\%$ of control & 1,000 -grain weight $(\mathrm{g})$ & $\%$ of control \\
\hline \multicolumn{7}{|l|}{ Regular } \\
\hline Control & $35.7 \pm 0.9 \mathrm{c}$ & 100.0 & $46.9 \pm 0.4 \mathrm{~b}$ & 100.0 & $46.9 \pm 1.4 \mathrm{~d}$ & 100.0 \\
\hline Medium-milk & $40.7 \pm 1.2 \mathrm{~b}$ & 114.0 & $52.5 \pm 0.5 \mathrm{a}$ & 111.9 & $60.2 \pm 1.4 \mathrm{~b}$ & 127.0 \\
\hline Late-milk & $41.0 \pm 0.3 \mathrm{~b}$ & 114.8 & $51.5 \pm 0.5 \mathrm{a}$ & 109.8 & $52.2 \pm 1.5 \mathrm{c}$ & 110.1 \\
\hline $\begin{array}{l}\text { Medium- and late-milk } \\
\text { Small }\end{array}$ & $47.5 \pm 1.5 \mathrm{a}$ & 133.1 & $51.6 \pm 0.5 \mathrm{a}$ & 110.0 & $68.7 \pm 1.4 \mathrm{a}$ & 144.9 \\
\hline Control & $17.9 \pm 0.3 \mathrm{c}$ & 100.0 & $17.3 \pm 0.4 \mathrm{~b}$ & 100.0 & $25.6 \pm 0.2 b$ & 100.0 \\
\hline Medium-milk & $22.1 \pm 0.2 \mathrm{a}$ & 123.5 & $24.0 \pm 0.6 \mathrm{a}$ & 138.7 & $29.9 \pm 0.1 \mathrm{a}$ & 116.8 \\
\hline Late-milk & $20.8 \pm 0.1 \mathrm{~b}$ & 116.2 & $22.7 \pm 0.4 \mathrm{a}$ & 131.1 & $26.5 \pm 0.1 \mathrm{~b}$ & 103.5 \\
\hline Medium- and late-milk & $22.0 \pm 0.1 \mathrm{a}$ & 122.9 & $23.4 \pm 0.2 \mathrm{a}$ & 135.3 & $29.1 \pm 0.2 \mathrm{a}$ & 113.7 \\
\hline
\end{tabular}

'Galil', 'Bait Hshita', and 'Gvati' grown under field conditions (2009-2010 season). CPAS was applied at the medium, late, and both medium and late milk stages. The controls were sprayed with the treatment solution without CPAS at medium milk stage. At maturity the regular (7.5-9.6 cm long) ears of each plot were separated from the small (5.0-6.4 cm long) ears and the two groups were mechanically threshed, for determination of the 1,000-grain weight. Vertical bars indicate plus or minus SE of the means $(n=6)$

senescence of the vegetative organs (Labrana and Araus 1991; Labrana et al. 1991; Beltrano et al. 1994) and increased grain weight (Beltrano et al. 1994, 1999). However, these inhibitors were examined only under controlled conditions. We previously reported that CPAS, a newly introduced water soluble ethylene antagonist, effectively abolished ethylene effects in various plant systems (Goren et al. 2011). Based on the negative relationship between the rate of ethylene production and grain yield, we examined whether this ethylene antagonist could increase wheat grain yield, focusing on field conditions. Wheat is one of the primary grains consumed by humans, and it is grown around the world in diverse environments. It is agreed that a substantial increase in grain yield potential is required to fulfill the world demand. Therefore, various strategies, particularly genetic ones, have been examined in order to increase the grain yield of wheat (Foulkes et al. 2009). The data of the present study indicate that CPAS might be one of the means to achieve this goal.

Except for one treatment (Table 2), application of CPAS at various grain developmental stages to several wheat cultivars grown under controlled (Fig. 3) or field (Tables 1 and 2) conditions significantly increased grain weight. This yield increase is usually presented in this report by the 1,000-grain weight, but similar results were also obtained by the determination of the grain weight per ear (Table 1 and data not shown). The shift of the grain weight per ear distribution curve, which is based on the average grain weight per ear, in CPAS-treated plants towards heavier grains further demonstrates the conspicuous effect of the CPAS treatments on the grain yield (Fig. 4 and data not shown).

Previous reports demonstrated that exogenous ethylene accelerated senescence, as was evident by rapid chlorophyll degradation in the flag leaves and vegetative parts of the ears (Beltrano et al. 1994), which could be delayed by inhibitors of ethylene biosynthesis and action (Labrana and Araus 1991; Labrana et al. 1991; Beltrano et al. 1994). We obtained similar data. Application of ethephon at the medium milk stage significantly reduced the chlorophyll content in most of the vegetative organs of cv. Gvati plants, and CPAS completely abolished this effect. Senescence of vegetative organs occurs gradually, leaving a time window, which allows modulating it by various means (Schippers Jos et al. 2007). Ethylene antagonists seem to be an effective tool for delaying senescence. Our data are inconclusive regarding the preferable timing of spraying under field conditions during this time window. In some cases spraying once at the medium milk stage was sufficient to obtain the maximum increase in yield (Table 2), while in other cases spraying twice at the medium and late milk stages yielded the highest increase in yield, Tables 1 and 2. More work is needed to determine the optimum timing of spraying for each cultivar.

The second experimental year (2009-2010) was characterized by extreme weather conditions, relatively high temperatures and a low winter rainfall. Heat and drought stresses are the major limitations to wheat production (Boyer 1982, Balota et al. 2004). In our experiments, the yield increase under controlled conditions (Fig. 3) and normal field weather conditions (Table 1) was about 20 and $15 \%$, respectively, whereas under extreme weather conditions, the yield increase in both regular and small ears was usually much higher, reaching about $45 \%$ in regular ears of cv. Gvati, compared to the control (Table 2). These data indicate that ethylene is involved in yield reduction under extreme weather conditions, and its effect could be 
abolished by ethylene antagonists. Similar results were obtained by Hays et al. 2007, when heat susceptible wheat cultivars were exposed to high temperatures. Although the data concerning ethylene production under water stress are inconclusive, Beltrano et al. (1999) reported that water stress significantly decreased grain yield, and this decrease was completely reversed by an inhibitor of ethylene biosynthesis.

Spraying CPAS on three rain-fed wheat cultivars in two successive years significantly confirmed the working hypothesis of the current research. In those experiments as well as in the earlier phytotron experiment a significant increase in grain yield was achieved. Therefore, the take home message of the current report is that the development of CPAS as an effective water soluble ethylene antagonist provides us with an agrotechnical tool to overcome the difficulties of the use of 1-MCP, either as a gas or wettable powder, in open environments (Burns 2008).

Acknowledgments We express our appreciation and gratitude to the Management of Volcani Center, ARO, for the privilege of carrying out the field experiments at the Experimental Farm, Bet Dagan. Thanks are also due to Dr. Uri Kushnir from The Volcani Center for his advice concerning the selection of the Wheat cultivars.

Open Access This article is distributed under the terms of the Creative Commons Attribution License which permits any use, distribution, and reproduction in any medium, provided the original author(s) and the source are credited.

\section{References}

Abeles FB, Morgan P, Saltveit ME (1992) Ethylene in plant biology 2nd edn. Academic Press, San Diego, p 414

Balota M, Cristescu S, Payne WA, te Lintel Hekkert S, Laarhoven LJJ, Harren FJM (2004) Ethylene production of two wheat cultivars exposed to desiccation, heat, and paraquat-induced oxidation. Crop Sci Soc Am 44:812-818

Beltrano J, Carbone A, Montaldi ER, Guiamet JJ (1994) Ethylene as promoter of wheat grain maturation and ear senescence. Plant Growth Regul 15:107-112

Beltrano J, Bartoli CA, Montaldi ER, Carbone A (1997) Emission of water stress ethylene in wheat (Triticum aestivum ol.) ears: effects of rewatering. Plant Growth Regul 21:121-126

Beltrano J, Ronco MG, Montaldi ER, Carbone A (1998) Senescence of flag leaves and ears of wheat hastened by methyl jasmonate. J Plant Growth Regul 17:53-57

Beltrano J, Ronco MG, Montaldi ER (1999) Drought stress syndrome in wheat is provoked by ethylene evolution imbalance and reversed by rewatering, aminoethoxyvinylglycine, or sodium benzoate. J Plant Growth Regul 18:59-64

Ben-Yaakov E, Harpaz-Saad S, Galili D, Eyal Y, Goldschmidt EE (2006) The relationship between chlorophyllase activity and chlorophyll degradation during the course of leaf senescence in various plant species. Isr J Plant Sci 54:129-135

Boyer JS (1982) Plant productivity and the environment. Science 218:443-448
Burns JK (2008) 1-Methylcyclopropene applications in preharvest systems: focus on citrus. HortScience 43:112-114

Cox WJ, Otis DJ (1989) Growth and yield of winter wheat as influenced by chlormequat chloride and ethephon. Agron J $81: 264-270$

Dias AS, Barreiro MG, Campos PS, Ramalho JC, Lidon FC (2010) Wheat cellular membrane thermotolerance under heat stress. J Agro Crop Sci 196:100-108

Foulkes MJ, Reynolds M, Sylvester-Brodley R (2009) Genetic improvement of grain crops: yield potential. In: Sadras NO, Calderini D (eds) Crop physiology applications of genetic improvement and agronomy. Elsevier, The Netherlands', pp 235-256

Gelanga J, Pleijelb H, Sildc E, Danielssonb H, Younisa S, Sellde'na G (2000) Rate and duration of grain filling in relation to flag leaf senescence and grain yield in spring wheat (Triticum aestivum) exposed to different concentrations of ozone. Physiol Plant 110:366-375

Goren R, Huberman M, Riov J, Goldschmidt EE, Sisler EC, Apelbaum A (2011) Effect of 3-cyclopropyl-1-enlyl-propanoic acid sodium salt, a novel water soluble antagonist of ethylene action, on plant responses to ethylene. Plant Growth Regul 65:327-334

Hays DB, Do JH, Manson RE, Morgan G, Finlayson SA (2007) Heat stress-induced ethylene production in developing wheat grains induces kernel abortion and increase maturation in susceptible cultivar. Plant Sci 172:1113-1123

Hiscox JD, Israelstam GF (1979) A method for the extraction of chlorophyll from leaf tissue without maceration. Can J Bot 57:1332-1334

Klassen SP, Bugbee B (2002) Sensitivity of wheat and rice to low levels of atmospheric ethylene. Crop Sci 42:746-753

Labrana X, Araus JL (1991) Effect of foliar applications of silver nitrate and ear removal on carbon dioxide assimilation in wheat flag leaves during grain-filling. Field Crop Res 28:149-162

Labrana X, Vendrell M, Araus JL (1991) Ethylene production in wheat flag leaves and ears during grain flling. Plant Physiol Biochem 29:349-354

Narayana I, Lalonde S, Saini HS (1991) Water-stress-induced ethylene production in wheat. Plant Physiol 96:406-410

Schippers Jos HM, Jing HC, Hill J, Dijkwel PP (2007) Developmental and hormonal control of leaf senescence. In: Gan S (ed.) Senescence processes in plants, Blackwell Publishing, Oxford, pp $145-170$

Sisler EC, Serek M (1997) Inhibitors of ethylene responses in plants at the receptor level: recent developments. Physiol Plant 100:577-582

Solansky S (1978) Distribution of assimilates within the ear of wheat. In: Spiertz JHJ, Kramer T (eds) Crop physiology and cereal breeding. In: Proceedings of Eucarpia Workshop, p 50. Wageningen, The Netherlands

Spano G, Di Fonzo N, Peroptta C, Palatani C, Ronga G, Lawlor DW, Napier JA, Shewry PR (2003) Physiological characterization of 'stay green' mutants in durum wheat. J Exp Bot 54:1415-1420

Wheeler RM, Peterson BV, Sager JC, Knott WM (1996) Ethylene production by plants in a closed environment. Adv Space Res 18:193-196

Wiegan CL, Cuellar (1981) Duration of grain filling and kernel weight of wheat as affected by temperature. Crop Sci 21:95-101

Yang J, Zhang J, Liu K, Wang Z, Liu L (2006) Abscisic acid and ethylene increased in wheat grains in response to soil drying during grain filling. New Phytol 171:293-303 